\title{
Construction of EFL Student Teachers' Beliefs about Method: Insights from Postmethod
}

\author{
Zhengping Zeng ${ }^{1}$ \\ ${ }^{1}$ School of Foreign Languages, Leshan Normal University, Leshan, China \\ Correspondence: Zhengping Zeng, School of Foreign Languages, Leshan Normal University, Leshan, Sichuan, \\ China. Tel: 86-158-8435-4565. E-mail: bzzhp888@126.com
}

Received: November 1, 2017 Accepted: December 8, 2017 Online Published: December 11, 2017

doi: 10.5539/elt.v11n1p93 URL: http://doi.org/10.5539/elt.v11n1p93

\begin{abstract}
Student Teachers' beliefs and their teaching behaviors are interactive and closely related. Student teachers' any adoption of teaching methods in micro-teaching or teaching practicum is largely hidden behind their beliefs. In this paper, starting with the origin and changes of methods in language teaching method era, the author explains certain terms such as method and postmethod, sorts out the theoretical base of this study which contains postmethod condition and postmethod pedagogy and proposes the idea that postmethod is the heritance, transcendence and development of method. Finally, the author discusses the ways to help student teachers construct their own proper teaching beliefs about method.
\end{abstract}

Keywords: English student teacher, foreign language teaching, beliefs about method, postmethod, teaching practice

\section{Introduction}

Since the People's Republic of China was founded, the Ministry of Education has published more than ten versions of National English Syllabus/Curriculum till 2011, all of which reflect the historical development of beliefs concerning method (BM) in China. With the influences of language teaching innovations in western countries, many scholars, among whom Zhang Shiyi is the most famous one, have advocated to adopt Direct Method in China from 1912 to 1949. After the founding of new China, due to the special relationship with former Soviet Union, Russian became the main foreign language learned in the language classrooms where Grammar-Translation has dominated from 1950 to1956. Till 1960s, Audio-lingual Method was advocated to adopt in the language classrooms. The long period of language teaching history from 1949 to 1976 can be generally divided into three stages: the development of Russian language teaching (1949-1956), initial recovery of English language teaching (1957-1965), and the destruction of English language teaching (1966-1976). Since then, English language teaching has developed rapidly, and Situational Language Teaching and Audio-lingual Method were mainly advocated in English language teaching in China assisted by Direct Method and the Inductive method. At the end of the twentieth century, Communicative Language Approach was widely used in language classroom followed by Task-based Language Teaching in the new century. Compared the previous Syllabus/Curricula with National English Curriculum for Compulsory Education \& Common Senior Middle Schools (2011), the former versions emphasize the specific use of methods, and the latter one lays much emphasis on the teaching beliefs, most of which are within the theoretical framework of postmethod. In fact, teachers' adoption of teaching methods is largely hidden behind their BM. English student teachers' BM has been explored in recent years. However, most of the researches are from the theorists' points of view. In this paper, the author intends to explore the way to help student teachers construct their beliefs about method from the perspective of postmethod, which is not only beneficial for student teachers to construct their own BM from their teaching practice such as micro-teaching, teaching practicum or classroom observation, but also to modify their previous BM.

\section{Method and Postmethod}

\subsection{Method}

Different people hold different views towards "method", there is no uniform definition in the field of English language teaching at present. There isn't any English word which is completely corresponding to "method" in 
Chinese. The Modern Chinese Dictionary (Chinese Academy of Social Science, 2005) defines "method" as "The way, procedure used to solve issues of thoughts, speeches and actions, etc." "Method" in English usually refers to method, approach or technique.

Obviously, the three conceptions are easily confused. A three-level method (approach, method and technique) identified by Anthony (1963) clarifies the confusion (See Figure 1). Approach is a set of correlative assumptions dealing with the nature of language teaching and learning. An approach is axiomatic. Method is an overall plan for the orderly presentation of language material, no part of which contradicts, and all of which is based upon the selected approach. A method is procedural. Technique is implemental-that which actually takes place in a classroom. It is a particular trick, stratagem, or contrivance used to accomplish an immediate object. Techniques must be consistent with a method, and therefore in harmony with an approach as well. In other words, different approaches and methods lead to different techniques.

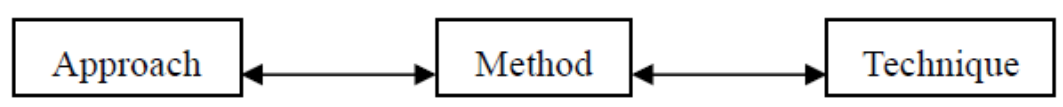

Figure 1. Levels of method

Following Anthony, Jack Richards and Theodore Rodgers (1982: 153-68) reconceptualized "method", and proposed that "method" is made up of three levels "approach, design and procedure", which are represented by "approach, method and technique" respectively. Method is only a concept of upper describing the three levels "approach, design and procedure" (See Figure 2). An approach defines assumptions, beliefs, and theories about the nature of language and languages learning. Designs specify the relationship of the theories to classroom materials and activities. Procedures are the techniques and practices derived from one's approach and design.

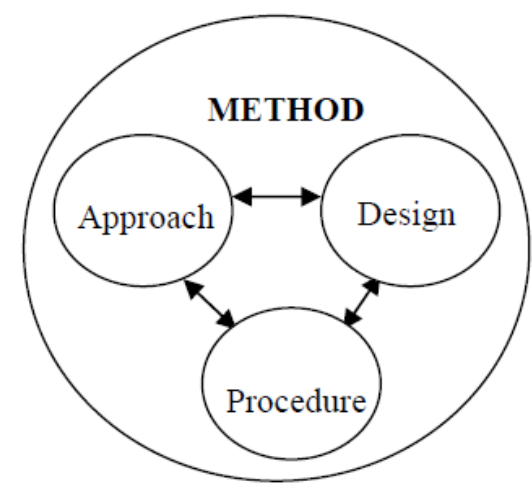

Figure 2. Three levels "approach, design and procedure"

\subsection{Postmethod}

At the end of 1980s, with criticism on the concept of method itself in the field of language teaching, Kumaravadivelu (1994: 29) first proposes the concept of postmethod, and redefines "method" as "consists of a single set of theoretical principles derived from feeder disciplines and a single set of classroom procedures directed at classroom teachers. The disciplines can be linguistics, psychology and sociolinguistics, etc., and we can use our own teaching procedures derived from our own teaching experience." As to postmethod, he regards it as a concept which signifies a search for an alternative to method rather than an alternative method. Postmethod is not one real teaching method, but a pedagogy which involves teaching strategy, teaching material, curriculum assessment and politics, history and personal experiences influencing foreign language learning.

\section{Brief Introduction of Postmethod Theory}

\subsection{Postmethod Condition}

Laying a solid foundation of postmethod pedagogy, postmethod condition includes three interrelated attributes. First, postmethod condition signifies a search for "alternative methods" rather than "alternative to methods" (Kumaravadivelu, 1994). While alternative methods are primarily products of top-down processes, alternatives to methods are mainly products of bottom-down processes (Kumaravadivelu, 2003). Products of top-down 
processes usually refer to theories constructed by theorists based on one or more theories, while products of bottom-down processes are the theories created by practitioners. On condition that "method" gives theorists the right to construct professional theories of pedagogy, the postmethod condition gives practitioners the authority to construct their personal theories of practice. Hunt (1980) also holds the view, "Whether implicit or explicit, theories of teaching and learning should be based on classroom experience: practice into theory". Palmer (1997) states: "Good teaching cannot be reduced to technique; good teaching comes from the identity and integrity of the teacher".

Theory is normally separated from practice, and practitioners are isolated from theorists. Then, the relationship between theorizers and practitioners should be refigured. What practitioners do is to construct their personal theories of practice based on the classroom experiences. Anyhow, to bridge the gap between the researchers and the practitioners is of great importance. Fitzgerald (2003) points out, theory and practice should inform each other, that is, theory should inform practice; it is also undoubtedly the case that practice should inform theory.

Secondly, postmethod condition signifies teacher autonomy (Kumaravadivelu, 1994). Autonomy implies a general idea that the individual should "freely direct the course of his or her own life" (Young, 1986). As to teacher autonomy, there is not a uniform definition at present. MacGrath (1995) defines it as capacity to self-direct one's teaching, Benson (2000) defines it as freedom to self-direct one's teaching and Smith (2003) argues that the concept of teacher autonomy has different dimensions as professional action or development (qtd. in Lamb, Terry, et al., 2008)(See Table 1).

Table 1. Dimensions of teacher autonomy

In relation to professional action:

\begin{tabular}{lll}
\hline A. Self-directed professional action & i.e. 'self-directed teaching' \\
\hline $\begin{array}{l}\text { B. Capacity for self-directed professional } \\
\text { action }\end{array}$ & $\begin{array}{l}\text { i.e. 'teacher autonomy (capacity to } \\
\text { self-direct one's teaching) }\end{array}$ \\
\hline $\begin{array}{l}\text { C. Freedom from control over professional } \\
\text { action }\end{array}$ & $\begin{array}{l}\text { i.e. 'teacher autonomy (freedom to } \\
\text { self-direct one's teaching)' }\end{array}$ \\
\hline In relation to professional development: & & \\
\hline $\begin{array}{l}\text { A. Self-directed professional } \\
\text { development }\end{array}$ & $\begin{array}{l}\text { i.e. 'self-directed teacher-learning' } \\
\text { B. Capacity for self-directed professional } \\
\text { development }\end{array}$ & $\begin{array}{l}\text { i.e. 'teacher-learner autonomy (capacity to } \\
\text { self-direct one's learning as a teacher)' }\end{array}$ \\
\hline $\begin{array}{l}\text { C. Freedom from control over } \\
\text { professional development }\end{array}$ & $\begin{array}{l}\text { i.e. 'teacher-learner autonomy (freedom to } \\
\text { self-direct one's learning as a teacher)' }\end{array}$ \\
\hline
\end{tabular}

The conventional concept of 'method' typically prescribes teachers what and how to teach, and there is often little room for the teacher's own personal initiative and teaching style (Richards \& Rodgers, 2008). However, the postmethod condition recognizes the teacher's potential to know not only how to teach but also know how to act autonomously within the academic and administrative constraints imposed by institutions, curricula, and textbooks (Kumaravadivelu, 2003).

The third attribute of postmethod condition is principled pragmatism (Kumaravadivelu, 1994). Principled pragmatism means that attitudes and actions are influenced by practical day-to-day consequences (Wenger, 2007). According to Widdowson (1990), the relationship between theory and practice, ideas and their actualization, can only be realized within the domain of application, that is, through the immediate activity of teaching. Thus, principled pragmatism focuses on how teachers shape and manage the process of specific English language learning as a result of self-reflection and critical assessment. Conducting classroom observation, writing journals and peer consultation are good ways to reflect and evaluate teaching.

As Kumaravadivelu (1994) points out, one of the ways in which teachers can follow principled pragmatism is to develop a sense of plausibility. A sense of plausibility (Prabhu, 1990) is "teachers" subjective understanding of the teaching they do. Teachers need to operate with some personal conceptualization of how their teaching leads 
to desired learning". In addition, such subjective understanding of language teaching is often derived from our own experiences as teachers or learners.

The above three attributes of postmethod condition lay a solid foundation on the construction of the three parameters of postmethod pedagogy.

\subsection{Postmethod Pedagogy}

Based on postmethod condition, Kumaravadivelu proposes postmethod pedagogy which is a three-dimensional system composed of parameters of particularity, practicality and possibility. The first parameter of postmethod pedagogy is the pedagogy of particularity. That is to say, language pedagogy must be sensitive to a particular group of teachers teaching a particular group of learners pursing a particular set of goals within a particular institutional context embedded in a particular sociocultural milieu (Kumaravadivelu, 2001). Context, which has been neglected in previous methodologies, is the crucial aspect of language pedagogy. The key aspects of the context are students' learning needs, wants, styles, strategies, as well as the coursebook, local conditions, the classroom culture, school culture, national culture, and so on (Bax, 2003). Compared with methods and approaches, context has the priority. Only when analyzing and understanding the contexts carefully and systematically can teachers utilize teaching methods and approaches automatically.

The pedagogy of practicality, the second parameter of postmethod pedagogy, pertains to a much large issue that has a direct impact on the practice of classroom teaching, namely, the relationship between theory and practice (Kumaravadivelu, 2001). The theory and practice are not simply the guiding and being guided relations, they mutually inform. A pedagogy of practicality, as Kumaravadivelu (1999) visualizes it, seeks to overcome some of the deficiencies inherent in the theory-versus-practice, theorists' theory versus teachers' theory dichotomies by encouraging and enabling teachers themselves to theorize from their practice and practice what they theorize. That is, the pedagogy of practicality aims for the teacher to construct a theory of practice.

The third parameter of postmethod pedagogy is the pedagogy of possibility. First, this parameter is regarded with students' and teachers' subject positions - class, gender, race, ethnicity, and the experiences that they bring to the pedagogical settings (Kumaravadivelu, 2001). The past experiences which tend to influence ESL/EFL learning/teaching could be shaped not only by learning/teaching environment but also social, political and economical environment. Secondly, this parameter is concerned with individual identity. Language education is a process in which participants seek for and construct their own identity. As Wendon (1987) indicates it, "Language is the place where our sense of ourselves, our subjectivity, is constructed". Thus, teachers and learners' identity should be preserved and protected in the classroom. Thirdly, language teachers can ill afford to ignore the social cultural reality that influences identity formation in the classroom, and nor can they afford to separate the linguistic need from the social needs (Kumaravadivelu, 2001).

From all above, the three parameters of postmethod pedagogy are interrelated, interacted, and interweaved, and their boundaries are blurred. As the following figure shows, the characters of these parameters overlap (See Figure 3).

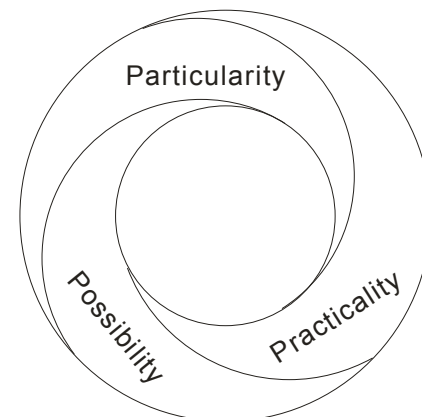

Figure 3. Parameters of postmethod pedagogy (Kumaravadivelu, 2003)

\section{Implications for EFL Teacher Education}

\subsection{EFL/ESL Teaching Methods/Approaches Training}

It is important to train the student teachers specific methods constructed in method era. Although we are in the postmethod era, method and postmethod do not conflict. Postmethod is just an alternative to method. Knowledge of methods is crucial to the development and growth of student teachers. Training of the techniques and 
procedures of a specific method is probably essential for student teachers' entrance into teaching, because it provides them with the confidence they will need to face learners and it provides techniques and strategies for presenting lessons (Richards, 2001). As Adamson (2004) mentions, methods are still useful props for teachers in constructing their own pedagogy. Ancker (2001) says, "I would not want to impose a method on anybody, but it seems to me the more methods we have, the more we see the variety of human experience, the more we have a bigger palette from which to paint our picture. We have more choices".

During the training of methods, we should change the transmission model of training as experts' lectures. According to the belief "theorizing from practice" in the theory of postmethod, we can train the student teachers based on teachers' own classroom experiences.

When training teachers the specific methods, it is unnecessary for us to argue what is the best method. Every method has its own advantages. What student teachers should do in their teaching practice is to select different methods based in the light of different learners, teaching objectives and learning stages. While selecting the methods, the student teacher should take these elements into consideration. For example, we can use the TPR more while teaching the first year middle school students differently from the third year middle school students, as the potential for losing face becomes greater the older the learners get (Harmer, 1998). Besides, student teachers should select methods in light of their own features. Otherwise, it will lead to Dongshixiaopin.

\subsection{Prerequisites of Implementing the Postmethod Theory}

The author argues that there are at least four prerequisites for the student teachers to implement postmethod theory in their classrooms. First, teaching experience is the precondition for implementing postmethod beliefs. The postmethod theory has many advantages. However, its philosophy is too idealistic and abstract. It is hard for the student teachers to grasp. To better carry out the language beliefs, a great amount of practical experiences are and fundamental and necessary, and the application of these beliefs contributes to a great deal of micro teaching practice, teaching practicum or classroom observation.

Secondly, understanding various methods or approaches is the basis of implementation of postmethod beliefs. The postmethod theory provides us an alternative to method, and relevant researches reveal that the student teachers lack the knowledge of methodology, that is, they are not familiar with the alternative methods. To better search for an alternative to method, student teachers should understand some alternative methods which are created by the theorists based on some language (learning) theories. Knowing some knowledge of methodologies will help them to form their own teaching beliefs.

Thirdly, constructing appropriate beliefs about methods is the guarantee of implementation of postmethod beliefs. Postmethod is a great challenge to most of student teachers. They might not know how to apply the beliefs although they often consider the theory or teaching beliefs are important. Only when they have the right beliefs about methods can they understand the real significance of the postmethod theory. Thus, an appropriate belief about methods is the key point to better put the beliefs into practice.

At last, the context-based research is a key step to ensure the successful implementation of postmethod beliefs. Context-based research is the research activity in which student teachers use some research methods to find out the solutions to the main problems and practical needs in their teaching. During the context-based research, student teachers can do some applied research or action research to practice the postmethod beliefs. The lesson example, which can be used to analyze the appliance of postmethod beliefs, is a good choice.

\subsection{A Training Model for Beliefs about Methods (BM)}

The author argues that it is very difficult for student teachers to construct their own teacher beliefs about methods (BM). So it is necessary to help student teachers establish proper BM in the teacher training courses. To achieve this goal, we can use lesson examples. After listening to the lesson example, teachers can be instructed to judge whether the selection or usage of certain method is appropriate, to reflect their teaching behaviors, teaching strategy and BM. And then, modify the used method to get a better one. Finally, their own teaching BM can be formed. The training model (See Figure 3) shows how to help student teacher to build their own teaching BM.

The dimension affecting the formation of BM is not simply the method itself; it contains many other elements such as the teachers' roles, the learners' roles, ELT Pedagogy. Richards and Rodgers say that method is a way of teaching a language which is based on systematic principles and procedures (2001). The systematic principles and procedures have been developed from different views of the nature of language, the nature of language learning, goals in teaching, the teachers' roles, the learners' roles, etc.

"Method" in "Teacher Beliefs about Methods" is at the level of methodology which relates to beliefs themselves 
(ditto). It is not at the level of method, approach, technique or skill. Teacher beliefs about methods determine the implementation of the classroom teaching. Figure 4 shows that there are four main ways student teachers can follow to form appropriate BM: learning knowledge about teaching skills, critical reflection, action research, and theorizing from practice. Besides, all the ways can be used to minimize the discrepancy between what student teachers believe and the ways they act in the classrooms.

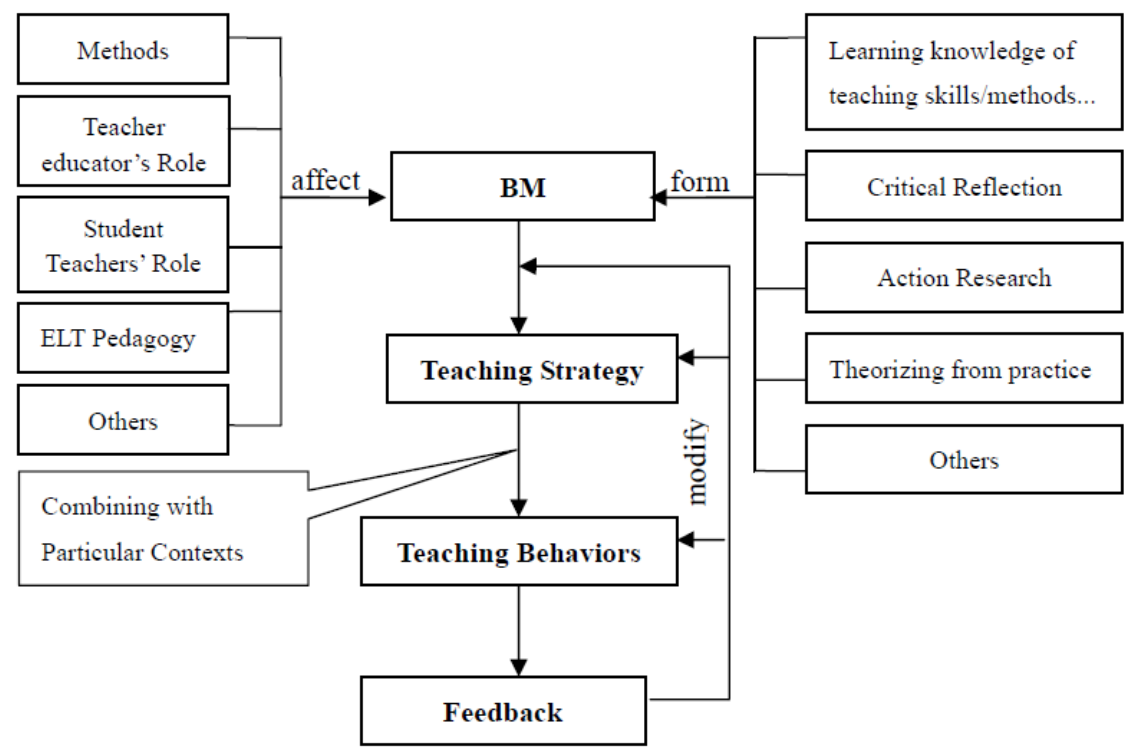

Figure 4. A training model for beliefs about method

\section{Conclusion}

When it comes to "method", what occur to student teacher's mind is the techniques she/he uses in the classroom. Based on the analysis of "method", the meaning of the term in a student teacher's mind is much different from that in a theorist's mind. The method created by theorists is a one-size-fits-all, cookie-cutter approach and can't meet different needs, situations of language teaching. One limitation of the very concept of "method" itself is that "method" neglects various complicated factors in language teaching such as society, politics, teacher's needs, student's needs, and culture and so on. On the contrary, postmethod greatly concerns about the above factors which have great influences on English language teaching and learning. Postmethod provides another alternative to methods, it provides us useful inspirations for student teachers, especially when they feel confused or at a loss towards the current popular complicated teaching methods. So it also empowers student teachers to theorize from their practice, and to be more autonomous. This research offers teacher educators the ways to help student teachers build their own teacher beliefs about methods.

\section{Acknowledgements}

The author would like to thank the Editor and the anonymous referees for their valuable and helpful suggestions. This research is financed by the Research Projects of Education Department of Sichuan Province (No.17SB0172).

\section{References}

Ancker, W. P. (2001). The joy of watching others learn: An interview with Diane Larsen- Freeman. Forum, 39(4), 2-9.

Anthony, E. (1963). Approach, method and technique. English Language Teaching, 17, 63-67. https://doi.org/10.1093/elt/XVII.2.63

Bax, S. (2003). The end of CLT: a context approach to language teaching. ELT Journal, 57(3), $278-296$. https://doi.org/10.1093/elt/57.3.278

Chinese Academy of Social Science. (2005). The Contemporary Chinese Dictionary. Beijing: The Commercial Press.

Fitzgerald. B. (2003). Informing Each Other: Bridging the Gap between Researcher and Practitioners. Informing 
Science, 6, 13-19. https://doi.org/10.28945/510

Harmer, J. (2000). How to teach English (1998 Longman Edition). Beijing: Foreign Language Teaching and Research Press.

Hunt, E. D. (1980). How to Be Your Own Best Theorist. Theory into Practice, 19, 287-293. https://doi.org/10.1080/00405848009542914

Kumaravadivelu, B. (1994). The postmethod condition: (e) merging strategies for second/foreign language teaching. TESOL Quarterly, 28(1), 27-48. https://doi.org/10.2307/3587197

Kumaravadivelu, B. (1999). Theorising Practice, Practising Theory: The Role of Critical Classroom Observation. In H. Trappes-Lomax, \& I. McGrath (Eds.). Theory in Language Teacher Education. London: Longman.

Kumaravadivelu, B. (2003). Beyond Methods: Macrostrategies for Language Teaching. New Haven and London: Yale University Press.

Kumaravadivelu, B. (2001). Toward a Postmethod Pedagogy. TESOL Quarterly, 35(4), 537-560. https://doi.org/10.2307/3588427

Lamb, T., et al. Eds. (2008). Learner and Teacher Autonomy. Amsterdam, Philadelphia: John Benjamins Publishing Company. https://doi.org/10.1075/aals.1

Palmer, P. J. (1997). The heart of a teacher: Identity and integrity in teaching. Change, 29(6), 15-21. https://doi.org/10.1080/00091389709602343

Prabhu, N. S. (1990). There is no best method—-why? TESOL Quarterly, 24(2), 161-176. https://doi.org/10.2307/3586897

Richards, J. C., \& Rodgers, T. S. (1982). Method: Approach, design and procedure. TESOL Quarterly, 16(2), 153-168. https://doi.org/10.2307/3586789

Richards, J. C., \& Rodgers, T. S. (2008). Approaches and Methods in Language Teaching (2nd edition). (2001 Cambridge Edition). Beijing: Foreign Language Teaching and Research Press.

Wendon, C. (1987). Feminist Practice and Poststructuralist Theory. London: Blackwell.

Wenger, Anna Frances Z. (2007). "The Role of Context in Culture-Specific Care". In P. L. Chinn (Ed.). Anthology on caring. NY: National League for Nurses.

Widdowson, H. G. (1990). Aspects of Language Teaching. Oxford: Oxford University Press.

Young, R. (1986). Personal Autonomy: Beyond Negative and Positive Liberty. London: Groom.

\section{Copyrights}

Copyright for this article is retained by the author(s), with first publication rights granted to the journal.

This is an open-access article distributed under the terms and conditions of the Creative Commons Attribution license (http://creativecommons.org/licenses/by/4.0/). 